\begin{tabular}{|c|c|}
\hline I & $\begin{array}{c}\text { International Journal of Current Research } \\
\text { and Academic Review }\end{array}$ \\
\hline 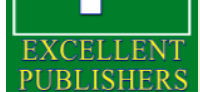 & $\begin{array}{c}\text { ISSN: 2347-3215 (Online) Volume } 7 \text { Number } 3 \text { (March-2019) } \\
\text { Journal homepage: http://www.ijcrar.com }\end{array}$ \\
\hline
\end{tabular}

doi: https://doi.org/10.20546/ijcrar.2019.703.009

\title{
The Effect of Maternal Presence toward Neonatal Death of Low Birth Weight in Aceh Province
}

\author{
Satrinawati Berkat*
}

Health Polytechnic of Aceh, Aceh Province, Indonesia

*Corresponding author:

\section{Abstract}

Low birth weight (LBW) is when a baby born with weight under 2,500 grams and is one of the primary causes of infant mortality in the world. Global prevalence rate of LBW is $15-20 \%$ of all birth. Maternal presence is one of the important factors related to neonatal survival of LBW. The purpose of this study is to assess the influence of the mother presence on LBW survival in the neonatal period. Observational study with the case-control method conducted within 8 districts/municipalities in Aceh province Indonesia and the data collection was started from February 2012 to August 2014. The population of the study was LBW babies who were born in Aceh Province between2011-2014. Total samples was500 of LBW babies. Single logistic regression used to bivariate analysis. The results showed that the percentage of the mother who took care of their babies in the neonatal period was $163(65.2 \%)$ in the case group and $211(84.4 \%)$ in the control group. The results of the simple logistic regression analysis found that there was a significant relationship between the presence of mothers and neonatal deaths, namely ( $\mathrm{p}<0.01)$ and odd ratio 2.88 (95\% CI: $1.87-4.43)$. The LBW babies who were not accompanied or took care by their mothers during the neonatal period were 2.8 times more likely to die compared to LBW babies who were accompanied or took care by their mothers. Indonesia government should be strengthening the Maternal and Child Health (MCH) services, starting from the prepregnancy until postnatal and onward thoroughly upgrading the monitoring and evaluation of MCH services.
\end{abstract}

\section{Introduction}

Birth weight is important to determine the health and survival of the baby in the neonatal period (0-28 days after birth). Low birth weight (LBW) is a serious problem related to the survival of new-born. LBW is a baby born weighing under 2,500 grams (WHO and

\section{Article Info}

Accepted: 04 February 2019

Available Online: 20 March 2019

\section{Keywords}

Maternal presence, Neonatal mortality and LBW 
of early growth retardation, infectious diseases, delay in growth and development and death (WHO, 2015). Meanwhile, the result of Indonesia Basic Health Research (Riskesdas) 2013 show that the prevalence rate of LBW in Indonesia was $10.2 \%$ of all birth (Kemenkes RI, 2013), and LBW is one of the leading causes of neonatal death. Relatively, a high number of LBW will contributes to a higher number of infant mortality (Kemenkes, 2008).

In 2015, an estimated 5.9 million children's under the age of 5 died, and $45.7 \%$ of them (27 million people) died in the neonatal period, and the main causes of neonatal deaths in the world were LBW, infection, asphyxia and birth trauma (WHO, 2015).

The actual number of LBW occurrence in Aceh Province was unknown, but based on the estimated birth number 2014 (i.e. 100,940), the estimate of LBW was 10,296 (Dinkes Aceh, 2015). Meanwhile, the number of infant deaths in the Province of Aceh in 2014 was 1,456 (1,056 or $72 \%$ occurred in the neonatal period), and $42 \%$ of these neonatal deaths were caused by LBW (Kemenkes, 2015). The five districts that have the highest cases of neonatal deaths in Aceh Province in 2014 were: Bireun, Pidie, Southwest Aceh, East Aceh, and Aceh Besar. (Dinkes Aceh, 2015).

The high estimation of LBW will increase the risk of neonatal death. Indonesia had been successful in reducing the infant mortality rate (IMR) in accordance with the Millennium Development Goals (MDGs) target. However, the decline was not as expected specifically for neonatal deaths (United Nation, 2015). Still, a high number of LBW raises concerns about the increasing of IMR in Indonesia same as the past.

Many cases of LBW and neonatal deaths, can be prevented if they can be characterized at an earlier stage. The World Health Organization (WHO) recommends several preventive measures to avoid neonatal deaths, these include: the attendant birth should be qualified of health personnel, home visits by the health workers, maintaining the baby's warmth, cutting the umbilical cord with sterile tools, initiating early of breastfeeding (IMD) and exclusive of breastfeeding (WHO, 2015). Besides these preventive measures recommended by the WHO, mothers presence for their babies and the mothers' health status during the neonatal period is also very important for the survival of their babies (WHO, 2014).
The presence of mothers taking care of their babies in the neonatal period is a great influence on neonatal survival. Previous studies concluded that the risk of death of babies whose mothers die after childbirth is greater than babies whose mothers survived in the neonatal period (Finlay et al. 2015; Maucheraud et al., 2011; Ronsmans, et al., 2010). In addition to the consequences of maternal death, maternal health status in the neonatal period also affects the survival of their baby (Finlay et al., 2015; Maucheraud et al., 2011).

Not many information related to the number of new-born babies who lost their mothers or did not take care by their biological mothers during the neonatal period. As an estimate, in 2015 there were around 830 maternal deaths every day due to the complications of pregnancy and childbirth. Thus, in 2015, there were approximately 300,000 new-borns whose mothers died and could not take care of them in the neonatal period (WHO, 2018).

Hence, the purpose of this study was to assess the influence of the mother presence on LBW survival in the neonatal period.

\section{Materials and Methods}

\section{Design}

An observational study with unmatched case control.

\section{Study site}

This study conducted in 8 districts in Aceh Province Indonesia, i.e. Aceh Besar, Pidie, Lhoksumawe, Aceh Utara, Aceh Timur, Aceh Tamiang, BenerMeriah and Aceh Tengah.

\section{Population and sample}

Population: LBW neonates who delivered between 2011 to 2014.

Sample divided into two groups:

a) LBW neonates who died in the neonatal period (case group)

b) LBW neonates who survived in the neonatal period (control group).

Total sample for this study was 500 (1:1), 250 cases and 250 control. 


\section{Data collection}

This study started from February 2012 to August 2014.

\section{Inclusion and exclusion criteria}

The criteria will be shown in table 1 .

\section{Instrument}

Questionnaire that filled by parent and assisted by enumerator.

\section{Variables}

Independent variable: presence of mother. This variable divided into two group: a). Presence, if the mother alive and taking care of her baby during the neonatal period (full day or only half day), b). Absent, if the mother died or alive but cannot treat her baby although only 2 hours a day in the neonatal period.

Dependent variable: Neonatal death, divided into two groups; neonate who died during the neonatal period (case group) and neonate who alive during the neonatal period (control group).

\section{Data analysis}

For univariate analysis used descriptive statistic, and single logistic regression for bivariate analysis.

\section{Results and Discussions}

\section{Descriptive analysis}

Characteristics of the neonates were shown in table 2 . Majority babies or neonates in the case group were boy i.e. $149(59.6 \%)$ and the majority in the control group was the girl (140 or 56\%). Characteristics of gestational age shown that most of the babies born at gestational age below 37 weeks or preterm birth i.e. 206 (82.4\%) in the case group and 147 babies or $58.8 \%$ in the control group.

Characteristics of mothers show in table 3, include: the mother who presence for took care of their baby according to the operational definition in this study was $163(65 \%)$ in the case group and $211(84 \%)$ in the control group. The characteristic age of mother shows that most of the case group, $182(72.8 \%)$ of mothers were in their 20-35 years of age and 211 (84.4\%) were in the control group.

Characteristic of birth interval show that were $165(66 \%)$ mothers in case group delivered with birth interval 2-5 years, and 201 (80.4\%) in the control group. The parity variable show that $134(53.6 \%)$ mothers in the case group and $147(58.8 \%)$ mothers in the control group delivery between 2-4 times when the study conducted. In the characteristic of maternal education level, 86 (34.4 $\%)$ mothers in case group graduated from senior high school and in the control group, 99 (39.6 \%) mothers graduated from senior high school.

Table.1 Inclusion and exclusion criteria

\begin{tabular}{|c|c|c|}
\hline Criteria & Cases & Control \\
\hline Inclusion & $\begin{array}{l}\text { 1. Born alive with birth weight } \\
\text { between } 1,001-2,499 \text { grams } \\
\text { 2. Born between } 2011 \text { to } 2014 \text { on the } \\
\text { study site } \\
\text { 3. Died before } 29 \text { days of life }\end{array}$ & $\begin{array}{l}\text { 1. Born alive with birth weight between } \\
1,001-2,499 \text { grams } \\
\text { 2. Born between } 2011 \text { to }-2014 \text { on the } \\
\text { study site } \\
\text { 3. Survive until } 28 \text { days of life }\end{array}$ \\
\hline Excl & $\begin{array}{l}\text { 1. Moved from the study site before or } \\
\text { during data collection } \\
\text { 2. Presence of congenital abnormalities } \\
\text { 3. Multiple births } \\
\text { 4. Hospitalized during neonatal } \\
\text { periods } \\
\text { 5. The neonate was adopted in the } \\
\text { neonatal period }\end{array}$ & $\begin{array}{l}\text { 1. Moved from study site before } \\
\text { ordering data collection } \\
\text { 2. Presence of congenital abnormalities } \\
\text { 3. Multiple births } \\
\text { 4. Hospitalized during neonatal } \\
\text { periods } \\
\text { 5. The neonate was adopted in the } \\
\text { neonatal period }\end{array}$ \\
\hline
\end{tabular}


Table.2 Characteristic of Neonates

\begin{tabular}{|c|c|c|c|c|}
\hline \multirow[t]{2}{*}{ Characteristic } & \multicolumn{2}{|c|}{ Case (250) } & \multicolumn{2}{|c|}{ Control (250) } \\
\hline & $\mathbf{n}$ & $\%$ & $\mathbf{n}$ & $\%$ \\
\hline \multicolumn{5}{|l|}{ Sex } \\
\hline - Girl & 101 & 40.4 & 140 & 56.0 \\
\hline - Boy & 149 & 59.6 & 110 & 44.0 \\
\hline \multicolumn{5}{|l|}{ Gestational age } \\
\hline - $\quad$ A term ( $\geq 37$ weeks $)$ & 44 & 17.6 & 103 & 41.2 \\
\hline - Preterm (<37 weeks) & 206 & 82.4 & 147 & 58.8 \\
\hline
\end{tabular}

Table.3 Characteristic of Mothers

\begin{tabular}{|c|c|c|c|c|}
\hline \multirow[t]{2}{*}{ Characteristics } & \multicolumn{2}{|c|}{ Case (250) } & \multicolumn{2}{|c|}{ Control (250) } \\
\hline & $\mathbf{n}$ & $\%$ & $\mathbf{n}$ & $\%$ \\
\hline \multicolumn{5}{|l|}{ Maternal Presence } \\
\hline - The mother died and the baby still alive & 0 & 0.0 & 2 & 0.8 \\
\hline $\begin{array}{l}\text { - The mother illness and did not take care } \\
\text { of their baby }\end{array}$ & 82 & 32.8 & 27 & 10.8 \\
\hline $\begin{array}{l}\text { - The mother healthy but could not take } \\
\text { care of their baby although only } 2 \text { hours } \\
\text { a day }\end{array}$ & 5 & 2.0 & 10 & 4.0 \\
\hline $\begin{array}{l}\text { - The mother illness but could took care } \\
\text { her baby although only } 2 \text { hours a day }\end{array}$ & 7 & 2.8 & 9 & 3.6 \\
\hline $\begin{array}{l}\text { - The mother healthy and took care of } \\
\text { their baby all day or only } 2 \text { hours a day }\end{array}$ & 156 & 62.4 & 202 & 80.8 \\
\hline \multicolumn{5}{|l|}{ Age } \\
\hline - 20-35 years old & 182 & 72.8 & 211 & 84.4 \\
\hline - $<20$ or $>35$ years old & 68 & 27.2 & 39 & 15.6 \\
\hline \multicolumn{5}{|l|}{ Birth Interval } \\
\hline - $2-5$ years & 165 & 66.0 & 201 & 80.4 \\
\hline$-<2$ or $>5$ years & 85 & 34.0 & 49 & 19.6 \\
\hline \multicolumn{5}{|l|}{ Parity } \\
\hline - Low Risk (2-4 times) & 134 & 53.6 & 147 & 58.8 \\
\hline - High Risk ( 1 or $\geq 5$ times & 116 & 46.4 & 103 & 41.2 \\
\hline \multicolumn{5}{|l|}{ Maternal Education level } \\
\hline - Elementary school & 55 & 22.0 & 47 & 18.8 \\
\hline - Junior high school & 80 & 32.0 & 68 & 27.2 \\
\hline - Senior high school & 86 & 34.0 & 99 & 39.6 \\
\hline - Diploma & 22 & 8.8 & 26 & 10.4 \\
\hline - Degree & 7 & 2.8 & 10 & 4.0 \\
\hline
\end{tabular}


Table.4 Bivariate analysis: The effect of maternal presence toward neonatal death on LBW babies

\begin{tabular}{lcccc}
\hline \multicolumn{1}{c}{ Variable } & $\begin{array}{c}\text { Group } \\
\text { Case (250) } \\
\end{array}$ & $\begin{array}{c}\text { Control (250) } \\
\mathbf{f}(\boldsymbol{\%})\end{array}$ & $\begin{array}{c}\text { OR } \\
\text { (\%) }\end{array}$ & P Value \\
\hline The presence of mother & & & \\
- Abstain & $87(34.8)$ & $39(15.6)$ & 2.88 & $<0.001 *$ \\
- Presence & $163(65.2)$ & $211(84.4)$ & $(1.87-4.43)$ & \\
& & & & \\
\hline *Significant variable: $p<0.05$ & & &
\end{tabular}

\section{Bivariate analysis}

In the result of the bivariate analysis found that the percentage of the mother presence to took care their babies in the neonatal period was $163(65.2 \%)$ in the case group and $211(84.4 \%)$ in the control group. The results of the simple logistic regression analysis found that there was a significant relationship between the presence of mothers and neonatal deaths, namely $(\mathrm{p}<0.01)$ and odd ratio 2.88 (95\% CI: 1.87- 4.43). LBW babies who were not accompanied or took care by their mothers during the neonatal period were 2.8 times more likely to die compared to LBW babies who were accompanied or took care by their mothers in the neonatal period.

The results of the bivariate analysis show that the presence of the mother in the neonatal period had a great influence on the neonatal survival of LBW babies in the Aceh province Indonesia. The LBW babies whom their mother were absent from took care them in the neonatal period (because the mother died, the mother illness or the mother healthy but could not take care of the baby) had the risk of dying almost 3 times greater compared to those babies who were accompanied by their mother and took care of them in neonatal period.

The results of this study have a quite similar results to a study conducted in California, United States in 2007, which concluded that mothers with hypertension were significantly associated with neonatal death of the LBW (Lee et al, 2007). Another study conducted in Thailand concluded that postpartum mothers with malaria were significantly associated with neonatal death of LBW babies. The LBW neonates who have a mother with malaria, have an 18 times greater risk of death compared to neonatal whose mother does not suffer from malaria (Luxemburgeret al, 2001). A research conducted in West Africa concluded that the presence of mothers greatly affects the survival of their children. Babies whose mothers die during childbirth have a 7 times greater risk of dying in the neonatal period than babies whose mothers alive (Scott et al., 2017).

The health and survival of the new-borns, especially LBW babies, are closely related to the presence of their mother. The absence of the mother or the inability of the mother in taking care of their baby will increase the risk of neonatal deaths. This due to the fact that the mother is the primary caregiver in caring for her baby and is somewhat irreplaceable (UNICEF, 2009). In addition, the presence and health of the mother will affect the nutrition of their babies. Early initiation of breastfeeding (IMD), colostrum and exclusive of breastfeeding can only be done if the baby has a healthy mother. The survival of LBW also strongly influenced by the nutrients that they getting during the neonatal period, and the best nutrition for the babies is breast milk, especially exclusive of breastfeeding (UNICEF, 2011).

Some of the previous studies concluded that there was a significant relationship between exclusive of breastfeeding and the neonatal death of LBW babies. The LBW babies who did not get exclusive of breastfeeding have a greater risk of dying compared to those accept exclusive of breastfeeding in the neonatal period (Edmond et al, 2005, Satrinawati, 2014). Exclusive breastfeeding can only be achieved when the mother an alive, healthy and able to provide this to her baby. In addition to the maternal health factors, several other factors that also determine the success of exclusive breastfeeding are maternal knowledge, positive attitudes, and information from the health workers about breast milk (Thaha et al, 2015).

Generally, Acehnese culture, as other culture in Indonesian societies, it is the mother who is the primary caregiver of her child from birth through breastfeeding. It is almost entirely impossible to replicate this by other family members where some remote cases do exist. Hence, the presence of a mother greatly affected the 
health and survival of her baby, especially for LBW babies who needed the extra care and nutrition compared to the babies born with normal weight. The results of this study greatly show that the presence of the mother was significantly related to the survival of LBW babies in the neonatal period.

Acehnese culture is almost the same as other culture in Indonesian society. Generally, the mother as the primary caregiver of her child from birth to the growing up. Besides as the main caregiver, the mother also as the main provider of nutrition for her child during the infancy period, through the breastfeeding. The position is difficult to replace by other family members, so the presence of mother greatly affected to the health and survival of their baby, especially for LBW babies who needed the extra care and nutrition compared to the babies born with the normal weight. The results of this study indicate that the presence of the mother was a significant association with the neonatal death of the LBW babies.

\section{Conclusion and suggestion}

The results of this study show that the presence of the mother was significantly associated with the survival of LBW babies in the neonatal period. The LBW babies who were not accompanied or took care by their mothers during the neonatal period were 2.8 times more likely to die compared to the LBW babies who were accompanied or took care by their mothers in the neonatal period. Suggestions to the government, especially the Indonesian Ministry of Health $(\mathrm{MOH})$ and the Provincial and District / Health Offices, to reduce the maternal absence in the neonatal period because of died or illness, the government should be strengthened the maternal health services, since pre-pregnancy until postnatal. Furthermore, monitoring and evaluation of maternal services should be increased, because based on the data, the number of maternal health services in health facilities increases every year but the maternal mortality is still high. This may be related to the manipulated data, so that monitoring and program supervision should be more intensive done by the $\mathrm{MOH}$ and Province/District health office to the community health center and others of the health facilities.

\section{References}

Dinas Kesehatan Provinsi Aceh. Profil Kesehatan Aceh Tahun 2014. Banda Aceh. Dinkes Provinsi Aceh. 2015
Edmond, K.M., Zandoh, C., Quigley, M.A., Etego, S.A., Agyei, S.O. and Kirkwood, B.R. Delayed Breastfeeding Initiation Increases Risk of Neontal Mortality. Pediatric journal. 2005.

Finlay, J.E., Moucheraud, C., Goshev, S., Levira, F., Mrema, S., Canning, D., Masanja, H., Yamin, A.E. The Effect of maternal mortality on infant and child survival in rural Tanzania: A Cohort Study. Maternal Child Health J. 2015; 1758-2

Kemenkes RI: Balitbangkes. Riset Kesehatan Dasar 2007. Jakarta. Kemenkes RI. 2008.

Kemenkes RI: Balitbangkes. Riset Kesehatan Dasar 2013. Jakarta. Kemenkes RI. 2013

Kemenkes RI: Profil Kesehatan Indonesia 2014.Jakarta. Kemenkes RI. 2015.

Lee, H.C and Gould, J.B. 2007. Survival rates and Mode of Delivery for Vertex Preterm Neonates According to Small- or Appropriate - for- Gestational- Age Status. Paediatrics Journal. 2007.

Luxemburger, C., McGready, R., Kham, A., Morison,. Cho. T., Chongsuphajaisiddhi. C., White, N.J and Nosten, F. Effects of Malaria during Pregnancy on Infant Mortality in Area of Low Maria Transmission. American Journal of Epidemiology. 2001. Vol 154, No. 5.

Maucheraud, C., Worku, A., Molla, M., Finlay, J. E., Leaning, J., Yamin, A. E. Consequences of maternal mortality on infant and child survival: a 25 year longitudinal analysis in Butajira Ethiopia (19872011). Reproductive Health. 2015; 12(54).

Ronsmans, C., Chowdhury, M.E., Dasgupta, S.K., Ahmed A., Koblinsky, M. Effect of parent's death on child survival in rural Bangladesh: A Cohort Study. Lancet. 2010; 375 (9730): 2024-31.

Satrinawati. Neonatal Survival Among Low Birth Weight Infants In Aceh Province, Indonesia. Desertasi Doktor. 2014. National University of Malaysia. Kuala Lumpur. Malaysia

Scott, S., Kendall, L., Gomez, P, Howie, S.R.C, Zaman, S.M.A., Ceesey, S, D’Alessandro, U, Jasseh, M. Effect of Maternal Death on Child Survival in Rural West Africa: 25 Years of Prospective Surveillance Data in The Gambia. Plos one. 2017.

Thaha, I.L., M. Razak, R. Ansaridi. Determinanpemberian ASI ekslusifolehibu multipara di Kabupaten Jeneponto. Jurnal MKMI. 2015; 247- 252.

UNICEF. The State of The World Children's 2009.United Nations Children's Fund. 2009.

UNICEF. 2011. A World Fit for Children Goal. http://www.childinfo.org/newborncare.html. [ May 15,2011). 
United Nations. The Millenium Development Goals Report 2015. United Nations. New York. 2015

WHO and UNICEF. Low birth weight. New York. WHO. 2007

WHO. Global Nutrition Target 2025: Low Birth Weight Policy Brief. New York: WHO. 2014

WHO. Maternal Mortality. https://www.who.int/news-room/fact-
sheets/detail/maternal-mortality.WHO. Update (16 February 2018)

WHO. Children: Reducing Mortality. New York: WHO. 2015

WHO. Newborn: Reducing Mortality. New York: WHO. 2015

\section{How to cite this article:}

Satrinawati Berkat. 2019. The Effect of Maternal Presence toward Neonatal Death of Low Birth Weight in Aceh Province. Int.J.Curr.Res.Aca.Rev. 7(3), 96-102. doi: https://doi.org/10.20546/ijcrar.2019.703.009 